thrown back as he looked directly above, he failed to notice that the board on which he was sitting was insecurely placed.

I had been watching the man, but had gone perhaps seventyfive feet away, when I heard a mighty crash, but no outcry. Calling out and receiving no reply, I hastened to the spot to find my man perfectly livid and completely unconscious. My first thought was that he had been killed, so free was he from all motion; no gasping and struggling, just an inert mass of flesh and blood.

The thought ran through my brain as I pulled his vest open to reach his heart, which, just as in Dr. Tuft's case, was beating, was that the distance the man had fallen had not been sufficient to produce such seemingly disastrous resulte. What was the trouble?

The man's mouth was open, and from it trickled a little tobacco stained saliva, hint enough to warrant my cramming my fingers down his throat and fishing out a great wad of moist fine cut that was simply packed in the back of the mouth, covering the trachea and extending down into it.

Hastily turning the man upon his face and giving him a few hearty thumps on the back, I had the satisfaction of seeing my patient within fifteen minutes cough himself back into lusty but somewhat profane existence.

The moral of my tale and that of Dr. Tufts is that the emergency physician should look out sharply for impacted quids. John E. BeEbe, M.D.

\section{Bureau of Public Health.}

United States Senate,

$\{$ Washington, D. C., Dec. 23, 1897.

To the Editor:-Your favor of the 16 th inst. has been received and read with interest. I note what you say with reference to the united effort on the part of the medical profession of our State, supported by the medical men throughout the country, in favor of the establishment of an independent bureau with a commissioner to be appointed by the President at its head.

There is no class of professional men in this or any other country more entitled to the highest consideration than that of the medical profession. Upon that profession the people always rely in times of physical distress in their everyday life, or in times when contagious diseases seize and threaten the lives of the people of a locality and the communities surrounding it, among whom the malady is likely to be spread.

I therefore should be very glad to be of service in any reasonable direction looking to the support and encouragement of the medical profession and also to the interest of the whole people. I think we have within a year or two had evidence that those in authority have failed in the performance of their whole duty in protecting the lives of the people against the ravages of yellow fever in certain portions of our country.

Wishing success in the conduct of the JourNaL OF THE American Medical Association, I am, sincerely yours, S. M. Cullom.

\section{National Legislation on Sanitation.}

Milwaukee, Dec. 29, 1897.

To the Editor of the New York Medical Journal:-In an editorial in the last issue of your valuable Journal there appears the following statement: "The American Public Health Association bill seems to us a retrograde measure. It would involve a departure from all existing methods of departmental work. It would create, to stand between the executive of the department and the management of an epidemic, a deliberative body of forty-five men whose opinions would have to be had before action could be taken."

Permit me to state that this is not the meaning or intent of the measure at all. It is intended that rules and regulations can be made by the department concerning which every State and Territory can have a voice, the only satisfactory way such rules and regulations can be adopted, and that such rules shall be standing provisions under which the head of the department can act at any moment when occasion occurs and without any delay whatever. No other bill thus far presented does more than provide for quarantine regulations, and such regulations are to be under the entire control of the Marine-Hospital Service. States are to have no voice in the matter, but must submit to the federal government. There are no provisions in any measure presented, except the bill presented by the American Medical Association and approved by the A merican Public Health Association at its last meeting, that provides in any way for internal sanitation, vital statistics, etc., so much needed, and which are far more important than the maritime quarantine provisions, which are but a small part of the needed sanitary legislation in this country. To say that the bill is retrograde seems to the writer to result from a very imperfect understanding of the measure. It is true that the bill as printed contains a number of errors and is more or lese ambiguous in its language. A new draft of the bili is being made, and when it is introduced into Congress it will present a clearer meaning and we trust will be less objectionable.

U. O. B. Wingate, M.D.

\section{Medical Courtesy.}

Shelbyville, INd., Jan. 11, 1898.

To the Editor:-I can not agree with you in your answer to R. A. H. on "Medical Courtesy," in the JournaL of January 8. My understanding is, and has been for more than forty years, that on this point of medical etiquette the rule is the reverse of that in social life, and for very obvious reasons. When a physician locates in a town, it is his duty to call on members of the regular profession at the earliest convenient time, if he is a regular physician himself. By this action he manifests his intention to continue in the regular profession and wishes to associate with its members.

He may, as is sometimes the case, be changing his location for the purpose of engaging in quackery, and to avoid any embarrassments, he should be left free to indicate his future intentions, which he can do in an emphatic manner by calling only on those of the regular profession.

Very respectfully, W. G. McFadden, M.D.

Boston, Jan. 10, 1898.

To the Editor:-In the Journal of January 8, page 104, "Medical Courtesy," I would suggest adding to the answer, but the newcomer should first leave or send his card as an introduction or announcement of his coming.

Respectfully,

J. S. W.

Ans.-Amendment is accepted.

\section{PUBLIC HEALTH.}

Influenza at Angers.--The French exchanges mention that the hospitals at Angers are full and patients turned away, from an epidemic of influenza.

Hospital Contagion of Typhoid Fever.-A number of instances were related at the meeting of the Paris Soc. Méd. des Hôpitaux in which patients and nurses in the hospitals acquired typhoid fever, presumably from other patients. Stricter precautionary measures were urged upon the attendants and the use of special vessels, etc., for typhoid patients.-Semaine Med., December 22.

Health in Chicago.-The report for December, 1897, gives the total deaths during the month as 1,790 , or 1.10 per 1,000 inhabitants, the rate for December, 1896, being 1.12 per 1,000 . Of these 1,790 deaths 361 were persons under 1 year old and 204 from 1 to 5 years. The causes were: Diseases of the nervous 